\title{
CAPÍTULO VI \\ Familia y socialización política en la democracia colombiana: Transferencia de valores políticos
}

\author{
Yolanda Rosa Morales Castro ${ }^{1}$ \\ Paola Ríos Mercado ${ }^{2}$
}

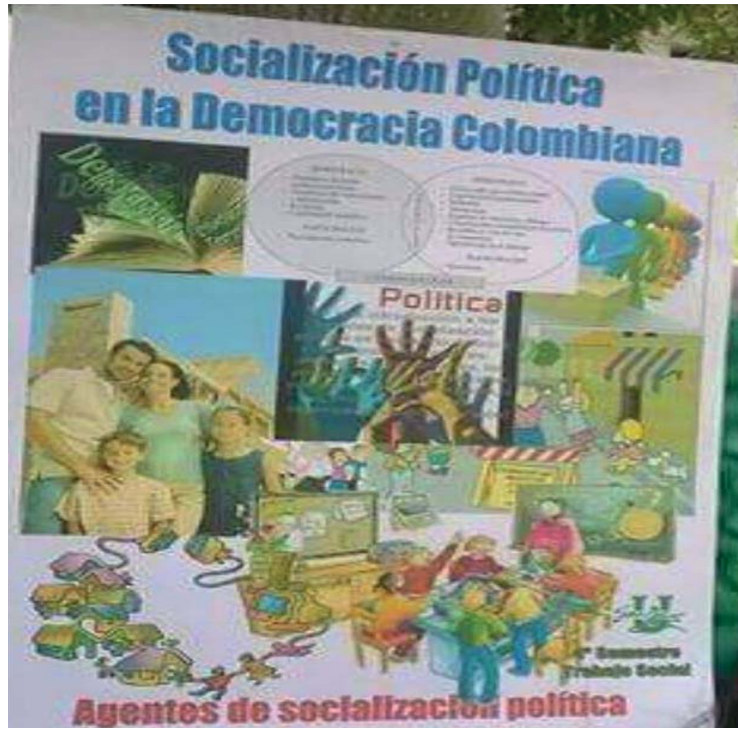

\footnotetext{
1 Trabajadora Social, especialista en Estudios Pedagógicos, Magístra en Desarrollo Familiar, doctora en Ciencia Política, docente e investigadora del grupo de Estudios de Género, Familia y Sociedad de la Universidad Simón Bolívar sede Barranquilla. ymorales@unisimonbolivar.edu.co

2 Trabajadora Social, co-investigadora. paorios0218@gmail.com
} 


\title{
RESUMEN
}

Mediante este estudio se indagó sobre el proceso de socialización política transmitido por la familia a los estudiantes de la Universidad Simón Bolívar, frente a las prácticas de democracia participativa y la transferencia de los valores políticos. La socialización política ha sido estudiada por diversos autores; en 1959, Hyman acuñó el término. En el marco metodológico se tomaron supuestos epistémicos presentes en la Ciencia Política que dieron cuenta de los agentes primarios y secundarios de socialización política. Desde el punto de vista paradigmático se trabajó bajo el macro-molde hermenéutico. Este estudio cualitativo, permitió obtener datos que se convirtieron en información, mediados por un ambiente natural y cotidiano donde estaban inmersos los estudiantes de la Universidad Simón Bolívar pertenecientes a las familias del Caribe colombiano. El análisis político se abordó desde el enfoque psicosocial, ya que bajo su óptica se ha estudiado el comportamiento electoral de los ciudadanos y el proceso de socialización política de las nuevas generaciones, entre otras. A manera de conclusión, es importante resaltar que la falta de información sobre la participación política, indica que no se dio en los estudiantes un adecuado proceso de socialización política por parte de la familia, lo cual expone a la población a un analfabetismo político, de tal manera que las prácticas de democracia participativa que adquieran los estudiantes dependerán de las características particulares de cada uno, de la red de interacciones, de otros agentes de socialización política, de la motivación, de la coincidencia política y del clima educativo y comunicativo familiar.

Palabras clave: Socialización política, familia, valores políticos, democracia

\begin{abstract}
Through this study we investigated the process of political socialization transmitted by the family to the students of the Simón Bolívar University in face of the practices of participatory democracy and the transference of political values. Political socialization has been studied by various authors; in 1959, Hyman coined the term. In the methodological framework were taken epistemic assumptions present in Political Science that gave account of the primary and secondary agents of political socialization. From the paradigmatic point of view one worked under the macro hermeneutic mold. This qualitative study allowed us to obtain data that became information mediated by a natural and daily environment where the students of the Simon Bolivar University belonging to the families of the Colombian Caribbean were immersed. The political analysis was approached from the psychosocial approach since under its optics the electoral behavior of the citizens and the process of political socialization of the new generations have been studied, among others. As a conclusion, it is important to emphasize that the lack of information on political participation indicates that the students did not receive an adequate process of political socialization on the part of the family, which exposes the population to political illiteracy, So that the practices of participatory democracy that students acquire will depend on the particular characteristics of each one, the network of interactions, motivation, political coincidence and the educational and communicative family climate.
\end{abstract}

Keyword: Socialization politics, family, political values, democracy. 


\section{Introducción}

Este capítulo muestra el resultado de un estudio piloto que fue insumo de la tesis doctoral en Ciencia Política intitulada, "La familia como agente de socialización en el sistema político de Colombia a partir de la instauración de la democracia participativa (1991-2014); de Yolanda Rosa Morales Castro, y expuesta en el II Seminario Internacional de Trabajo Social Reinventando saberes para la intervención social en los nuevos territorios de paz. En la presentación de la ponencia la autora enfatizó sobre la necesidad de profundizar en la temática a fin de sistematizar para intervenir desde lo político y social. El objetivo del estudio permitió indagar sobre el proceso de socialización política transmitido por la familia a los estudiantes de la Universidad Simón Bolívar frente a las prácticas de democracia participativa y la transferencia de los valores políticos. Dentro de la indagación emergieron categorías que dieron cuenta de los resultados, los cuales se ampliaron con los referentes en el marco de la socialización política y la democracia participativa. Se finaliza esta presentación dando cuenta de la discusión y conclusiones, producto de los resultados obtenidos con un tinte ideológico y político en defensa de la democracia como modo de vida.

\section{Marco teórico}

\section{Socialización de valores políticos desde la familia}

Desde la psicología social y la ciencia política, entre otros ámbitos de estudio, la socialización política se ha convertido en un tema de gran importancia, debido a que influye en las normas y valores que se adquieren en una sociedad y está orientada hacia la participación en el espacio público, la construcción de ciudadanía y la apropiación de una determinada ideología política.

En el tema de la socialización política actúa un conjunto de instituciones, organizaciones y personas que obran como orientadores y facilitadores del aprendizaje de lo político, ellos influencian al individuo por vía directa e indirecta. En el primer caso porque aquellos agentes especializados en la política asumen la conducción de la formación política, y en el segundo caso, porque aquellos 
agentes de socialización cuyas funciones no son específicamente políticas, predisponen hacia orientaciones, valores, imágenes y símbolos que colaboran a hacer factibles determinados comportamientos políticos, ya que los individuos adquieren elementos significativos para comprender y vivir en democracia.

La socialización política la expresan como el proceso de consolidación de valores explícitamente políticos del ciudadano. Anduiza y Bosch (2004) argumentan que, "los individuos aprenden y modifican los contenidos del mundo que han legado de sus antecesores" (p.26).

La socialización de la política no es solo un asunto de educación y contenidos curriculares, en él también interviene el concepto de que el individuo se ha formado de ella como resultado de los agentes primarios y secundarios y, de igual manera, de los factores culturales que determinan en gran medida el grado de participación o no de las personas en los asuntos relacionados con la política.

Pereira (2001) define la socialización política como "aquellos mecanismos y procesos de formación y transformación de los sistemas individuales de representación, de opiniones y de actitudes políticas, se puede determinar la magnitud de la importancia que esta tiene para el desarrollo de la democracia" (p. 336).

Teniendo en cuenta los diferentes aportes teóricos y perspectivas, se puede definir la socialización política como aquel proceso mediante el cual un individuo va adquiriendo valores, costumbres y creencias, las cuales son transmitidas y se adquieren en un medio social con la finalidad de establecerse en un orden político.

En opinión de Barreda (2006),

Los individuos están provistos de un conjunto de actitudes, valores, creencias y conocimientos sobre la política, estas pautas culturales no 
son innatas, los individuos las asumen e interaccionan a lo largo de su vida. El proceso mediante el cual los individuos adquieren estas pautas culturales transmitidas de generación en generación se conoce como socialización política. (p.207)

En el proceso de socialización política hacen presencia varios agentes de socialización, los agentes primarios representados en la familia y los secundarios en la escuela; los amigos o grupos de pares; los medios de comunición y los partidos políticos. En este estudio se profundizó en la familia como agente primario de socialización política.

La familia es considerada el agente de socialización primaria por excelencia puesto que "La familia es el primer lugar de transmisión de la cultura. Forma parte de una sociedad que se rige por normas. Estas son modos de regulación de la conducta informal que se van generando fundamentalmente por la tradición. La familia y particularmente la pareja, deben actuar de tal forma que aseguren la transmisión de estas normas a través de la función de socialización, esto es mediante la crianza y educación de los hijos. (García, 2008, p.17)

Articulando los conceptos, el proceso de socialización política vincula a la familia en la socialización de los valores políticos que induce a sus miembros a participar en la democracia colombiana. Al respecto Villarroel (2001) concluye: "se muestra que el interés en la política y las convicciones democráticas están asociados con experiencias favorables de socialización política primaria" (p.283).

Anduiza y Bosch (2004) plantean que "La socialización familiar es, pues la principal causa de los valores políticos de los individuos, y eso es algo muy importante, ya que estos valores tendrán una influencia directamente sobre el voto" (p.193). Estos autores hacen referencia a los valores políticos cuando se 
transfieren ideologías izquierda-derecha, identificación con un partido político o nacionalismo

La socialización temprana influye sobre las percepciones de los miembros de las familias pero no implica que la internalización de códigos valorativos, los esquemas perceptivos y las actitudes no puedan sufrir modificaciones producto de experiencias posteriores más directamente vinculadas con el área política. Los individuos utilizan los valores políticos como procesadores de información política.

De acuerdo a la Constitución Política 1991, Colombia cuenta con un régimen democrático, el cual permite que los miembros de la sociedad participen y ejerzan su democracia enmarcada en los valores políticos, para lo cual es importante un proceso de socialización primario y secundario responsable y serio, que permita interiorizar unos valores políticos encaminados a la participación, los cuales se pueden orientar hacia la emisión del voto, participación en actividades de las campañas electorales, afiliación en los partidos políticos socializando la política, elección de los cargos públicos, a la formulación, elaboración y aplicación de políticas públicas, perteneciendo a asociaciones, organizaciones o participación en actos de protesta política, entre otras.

En este mismo sentido Vásquez, (2010) expresa que entre mayor sea el interés por la política y mayor el grado de socialización política, se formarán más ciudadanos virtuosos para la democracia.

El tema de la familia como agente primario de socialización política se estudia en el marco de la democracia colombiana, de ahí la importancia de conjugar la socialización política con la democracia, ya que la democracia juega un papel decisivo en las sociedades, contribuyendo a un mejoramiento de la calidad de vida, la justicia y equidad social siempre y cuando se apliquen adecuadamente sus principios y el interés del pueblo por participar en la democracia, haciendo uso de los mecanismos de participación. 
En opinión de Sartori (1988) la democracia siempre se muestra como una palabra ambigua por la comprensión y la práctica que se tenga de ella, pero si se define literalmente, se presenta como transparente en consideración a que siempre está sujeta a un significado original; se define como el gobierno o el poder del pueblo.

El término democracia sufre interpretaciones diversas, y de una cultura a otra sufre variaciones y trasformaciones que resultan en una complejidad hacia el discernimiento de la palabra para tomarla como piedra angular en la estructuración de una hipótesis, o de una teoría que queramos construir, o que pretendamos explicar o entender la que otros han desarrollado.

Para Sartori (1988), democracia tiene una acepción denotativa o descriptiva en el marco del deber ser (lo ideal), y la prescriptiva o normativa que a su vez la valida por cuanto considera que ella es posible, mientras existan valores ó ideales que la crearon. Para él hay una gran diferencia entre la realidad conocida, con sus diversas definiciones y el ideal que efectivamente transmite su significado: El gobierno del pueblo.

En países como Colombia la socialización se ha convertido en un aporte fundamental para la formación de personas democráticas. Al respecto Arciga (2004) dice: "La socialización política puede contribuir a la formación de un ciudadano democrático informado, interesado, activo, sensible a los derechos humanos y consciente de la relevancia de su participación social” (p.382).

En Colombia impera la desigualdad e inequidad, la concentración de poderes, monopolios políticos, riquezas en manos de unos pocos y un sinnúmero de hechos que han suscitado en la población la pérdida de fe y credibilidad en los entes de control público y los mandatarios, razón por la cual se ha disminuido en gran porcentaje la participación activa de la ciudadanía en los valores democráticos. 
En la actualidad cabe destacar que los niveles de violencia en torno a la socialización política han disminuido de manera considerable, han surgido nuevos partidos políticos y aún se mantienen los tradicionales, el desarrollo de la tecnología, las transformaciones y el surgimiento de nuevas tipologías de familia han logrado que la socialización política se asuma de otra manera.

La actitud política juega un papel fundamental en el tema de la participación ya que se relaciona con las creencias y valores que interiorizan los sujetos para guiarlos en la construcción de su pensamiento respecto a un asunto. La actitud política con que se construyen las representaciones sociales proviene a partir de las predisposiciones adquiridas por los ciudadanos, las cuales se manifiestan a través de distintas formas de participación política.

(...) la participación política es asociada con una forma diferente de hacer política, la cual busca el mantenimiento de la comunidad a través de diversas actividades como el establecimiento de la comunicación pública para la solución de las disputas existentes y la cooperación entre los miembros individuales y grupales pertenecientes a la comunidad en cuestión. (Franco y Flores, 2009 p.82)

\section{Antecedentes}

En una exploración inicial realizada a un grupo de jóvenes universitarios se obtuvo como resultado que la mayoría reconoce la importancia de la democracia para el desarrollo de un país, sin embargo, hay contraposición de la incidencia que tiene la familia en el proceso de socialización política; algunos afirman que se encuentra vigente y otros que ha perdido protagonismo.

Hyman (1959) efectúa una revisión sobre las investigaciones realizadas hasta el momento, asimismo hizo parte de la corriente Behaviorista; sus estudios se caracterizaron por favorecer el mantenimiento del orden social imperante, también miraban a los sujetos como agentes pasivos en los procesos de socialización. Uno de los principales resultados de estas investigaciones estaban re- 
lacionados con la socialización política primaria en donde Hyman refiere: "la mayoría de las personas adquiere una afinidad ideológica aun antes de tener un conocimiento razonable sobre la política", lo que conlleva a considerar la permanencia de las inclinaciones políticas a través del tiempo.

Rincón (2012) presenta un análisis sobre la relación entre socialización en la familia, formación ciudadana y convivencia democrática. Se fundamenta en un proyecto de investigación realizado en Cali entre los años 2009 y 2011, en el cual se interpretaron los relatos de estudiantes universitarios acerca de su vida familiar, teniendo en cuenta aspectos nucleares de la ciudadanía tales como: valores cívicos, participación, ejercicio de derechos y de responsabilidades, reconocimiento de la diversidad, interés por la vida pública, manejo del conflicto, entre otros.

Greinstein (1965) aportó la primera información empírica sobre las afinidades ideológicas transmitidas de padres hacia sus hijos en Norteamérica. La investigación dio cuenta de las inclinaciones políticas de los niños, quienes a muy temprana edad se definían de un partido u otro, mostrando correspondencia con el partido político al que pertenecían sus padres.

Jaime (2000) realizó un estudio donde se tomaron los datos de cinco encuestas realizadas sobre cultura política y económica, en la cual se les solicitaba a ciudadanos españoles mayores de 18 años que se ubicaran ellos y a sus padres en una escala de diferencial semántico izquierda-derecha. Este estudio tuvo como prioridad determinar la ubicación ideológica de los padres e hijos sobre el continuum izquierda-derecha. Dentro de los resultados se encontró que los hijos suelen compartir con sus padres las actitudes políticas básicas, encontrándose una reducida distancia ideológica entre padres e hijos, aunque existe una pequeña tendencia de estos hacia la izquierda. Concluye que padres e hijos suelen compartir las normas políticas e ideológicas desde la infancia, siendo la familia aún el principal agente socializador político. 
Otra investigación que cobra gran importancia es la socialización política y juventud: es el caso de las trayectorias ciudadanas de los estudiantes universitarios de la región de Valparaíso, realizada por Sandoval y Díaz (2010). Los resultados indicaron que los jóvenes sometidos a una mayor socialización política en sus familias de origen, suelen manejar mayor información sobre estos temas y tienden a adoptar una postura política más definida. Así mismo se concluyó que la familia sigue siendo uno de los pilares instituciones de socialización a través de medios explícitos e implícitos.

\section{Agentes primarios de socialización política}

La denominación de los agentes primarios gira en torno al autor que los defina. A la familia como el agente primordial de la socialización no se debe a que sea el primer agente que actúa sobre el niño, sino al carácter cualitativo de su influencia. Por otro lado, si hablamos de la familia como agente de socialización es porque no sólo son agentes socializadores los miembros de la pareja. (Cardús, 2003, p.46)

Lo anterior precisa que la socialización no se genera en una sola dirección. Por su parte, otros autores reconocen a la familia como agente primario de socialización, sin embargo la acompañan otros agentes tal como es el caso de Arnoletto (2007), el cual opina que los agentes primarios corresponden básicamente a la familia y los grupos de pares. La familia es la fuente de conocimiento inicial de toda realidad y de toda valoración, incluyendo, por cierto, la política. Es también el foco de interés y relaciones efectivas personales durante el período formativo inicial del individuo. El grupo de pares, grupo de amigos, de compañeros de escuela, de colegas de trabajo, de vecinos del barrio cobra especial importancia desde la primera adolescencia; es una fuente de información sobre el mundo y un filtro de interpretación de los acontecimientos.

Puede producirse por medio de los mecanismos: mediante la transmisión de valores de interés por lo público, compromiso, solidaridad o cooperación, y mediante el aprendizaje de pautas cooperativas gracias 
a las prácticas realizadas por figuras de referencia como los padres, los compañeros de escuela o los profesores. (Montero, 2006, p.167)

Los valores que se transmiten en esta fase del proceso de socialización suelen dejar huellas importantes en las concepciones de los individuos sobre la política. Sin duda alguna, la familia es considerada el agente primario de socialización y una pieza clave en este proceso. En este mismo sentido Puga (2007) señala que "el individuo adopta los principios de orientación básica de su comportamiento social” (p.215). Sumando a la apreciación anterior, la de Villaroel (2001), se colige que "Muestra que el interés en la política y las convicciones democráticas están asociados con experiencias favorables de socialización política primaria” (p.61).

Por su parte, Benedicto (2005) sostiene que el papel destacado del ámbito familiar y educativo en determinadas etapas del ciclo de los individuos está fuera de toda duda, así como la impronta que la acción socializadora de los padres y educadores deja sobre las percepciones del mundo social y político de las nuevas generaciones. Sin embargo, ello no debe ser obstáculo para reconocer la relevancia de otras instituciones de socialización y de otros ámbitos en el que el individuo también se socializa particularmente a lo largo de su vida.

\section{Agentes secundarios de socialización política}

Los agentes secundarios cumplen con una función importante dentro de este proceso de socialización política, porque también contribuyen a la construcción de ideas en torno a la política y asuntos relacionados a esta, tal como lo es la democracia. Entre los agentes secundarios se encuentran: la escuela, los grupos de pares y los medios de comunicación; sin embargo, estos varían dependiendo del autor que los defina. Ejemplo de una forma de ver y asumir los agentes secundarios es la propuesta de Cardús (2003), el cual considera a la familia como el agente socializador primario; sin embargo reconoce la existencia e importancia de los agentes secundarios. 
Por otro lado, apropiándose de un enfoque de psicología social se define el proceso de socialización política secundaria "como internalización de submundos institucionales, que se desarrollan en contextos en los cuales las interacciones humanas están mediadas más por los intereses institucionales y por las prácticas que allí se desarrollan" (Tonon, 2009, p.68).

Los grupos primarios son básicamente, la familia y los grupos de pares. Los grupos secundarios son básicamente, las instituciones educativas y las asociaciones, voluntarias. Aparte y especialmente para las sociedades modernas, hay que considerar el papel de los medios de comunicación social. (Arnoletto, 2007, p.223)

Según Arnoletto (2007), las instituciones educativas, el esfuerzo por distribuir conocimiento y afirmar la vigencia de valores políticos son explícitas y directas, y responde a una necesidad social evidente. De igual manera expresa que las asociaciones voluntarias (políticas, culturales, deportivas, recreativas, religiosas, entre otros) operan como agentes de socialización política. Son promotoras de actividades formativas, de educación y difusión, que directa o indirectamente influyen en la orientación política de sus adolescentes, simpatizantes y público en general.

Por último precisa que los medios de comunicación social son, para la mayoría de la población, la forma de interpretación de los hechos de la vida política, nacional e internacional. Son muy pocos los que acceden a una información de otro origen: libros científicos, contactos directos, viajes, entre otros. Por su parte, Pérez (2006) señala que la familia es el agente por excelencia, pero además existen otros agentes tales como la escuela, los medios de información y, de manera más reciente, a los grupos de pares. Este autor a su vez define cada uno de los agentes secundarios como se expresa a continuación.

La escuela encuentra a infantes que ya llevan una fuerte carga de los hogares y de su exposición ante los medios; no obstante, en otros rubros, 
la escuela, o su entorno, posibilita que los infantes se involucren en ciertas formas organizativas. Los medios de comunicación, sobre todo la televisión, son influyentes desde dos aspectos: los programas dirigidos a grupos de edades son más frecuentes, creando incluso subculturas, y sus contenidos suelen tematizarse en los grupos de pares, en otro sentido juegan como filtros de la información que llega a niños, jóvenes o adultos. Los grupos de pares tienen un papel fuerte; en muchos casos es la escuela el espacio de encuentro y de interacción de estos. En efecto, la importancia de los grupos de pares crece cada vez más en cuanto a socialización política se refiere, pues son vehículos eficaces de comunicación y transmisión de actitudes y valores de diversa índole.

Proceso de integración al sistema político, a sus reglas y a su lógica de funcionamiento. Los principales agentes de socialización secundaria son los partidos políticos que hacen proselitismo entre la población a favor de sus concepciones de doctrinas y programas políticos. (Puga, 2007, p.215)

Los agentes secundarios cumplen con una labor ampliamente reconocida en el proceso de socialización política y su denominación dependerá del autor que se referencie en el estudio. Desde una perspectiva integral y actual de abordaje de la socialización política, trabajada, principalmente por Percheron (1990), se entiende que el orden social es complejo y contradictorio y, por ende conflictivo, por lo tanto, el individuo realiza a lo largo de toda su vida una continua síntesis creadora de las imágenes contrapuestas que recibe de los diferentes agentes de socialización.

\section{Enfoques para el análisis político}

En el tema de la socialización política no podemos dejar de conjugar el comportamiento político electoral y el papel que juegan los enfoques sociológicos, psicológicos y económico/racionales, que han inspirado muchos estudios 
sobre comportamiento electoral, como también, los factores a corto y largo plazo. Siguiendo a Molina (2000), se entiende por enfoque una forma de aproximación teórica a un problema de investigación, que implica la existencia de un modelo explicativo general. Este modelo puede ser más o menos complejo, y en última instancia está ligado a interpretaciones generales acerca de lo social y lo político y a concepciones filosóficas e ideológicas.

Pérez (2006) argumenta que los enfoques derivan en el uso predominante de ciertos tipos de características para explicar las decisiones y conductas; en este caso particular, conductas de voto. Estos enfoques se han clasificado para su análisis en: enfoque sociológico, psicológico y económico/racional. Cada enfoque contempla perspectivas teóricas diferentes que han sido predominantes en el estudio de la participación electoral.

A continuación se detallan los siguientes enfoques:

\section{Enfoque sociológico}

Uno de los factores de primer orden en esta perspectiva sociológica es el nivel socioeconómico, en el cual varias investigaciones han encontrado asociarlo positivamente con la participación electoral Milbrath y Goel (1977), Pasquino (1988), (Bennet y Bennet (1989), Conway (1986), Wolfinger y Rosentone (1980). Por otra parte, Pérez (2006) plantea que en este enfoque las condiciones sociales son los principales determinantes de la abstención, tanto en el nivel individual como en el agregado. Estas condiciones hacen referencia a varios elementos de tipo demográfico tales como la edad, el género, el ingreso y la ocupación, así como al entorno social: clase social, religión, etnia, comunidad lingüística. Mientras más alto es el nivel socioeconómico, la participación electoral es más frecuente.

\section{Enfoque psicológico}

El trabajo publicado por Campbell, Converse, Miller y Stokes (1960) plantea 
un modelo explicativo del voto basado en variables de tipo psicológico. La decisión de voto se concibe como resultado de múltiples factores que actúan a corto y a largo plazo, y tanto de naturaleza propiamente política como no política, que incluyen creencias, valores, actitudes y sentimientos. El enfoque psicológico privilegia las explicaciones individuales y el efecto de las actitudes de los ciudadanos sobre la participación electoral. Pérez (2006) considera que esta orientación teórica y metodológica hace un énfasis mayor en los individuos y en los procesos mentales que anteceden a una decisión electoral.

\section{Enfoque económico/racional}

El modelo teórico que sustenta este enfoque parte de una concepción diferente de la práctica democrática. Iniciado por Downs (1957), plantea la aplicación de los supuestos de racionalidad económica a la esfera política. El fundamento de esta teoría estriba en que el individuo se comporta racionalmente cuando toma decisiones políticas; esta racionalidad significa que el individuo vota por la opción que él supone le produce mayores beneficios.

\section{Fundamentos metodológicos}

La investigación en su responsabilidad ética fundamentó su recorrido teórico-empírico-metodológico desde la investigación cualitativa, ya que se enfocó en comprender los fenómenos, explorándolos desde el ambiente natural de los participantes y en relación con su contexto.

Siguiendo lo planteado por Hernández (2014), la investigación cualitativa es un proceso circular y flexible, el cual permite regresarse a etapas previas si la investigación lo requiriere, cuyo propósito es reconstruir la realidad tal y como se observa, en un ambiente natural y cotidiano, desde la perspectiva de los sujetos involucrados en el estudio sin que en esta exista manipulación o reducción de la realidad.

En este sentido, a través del enfoque cualitativo se indagó cómo se dio el pro- 
ceso de socialización política transferido por las familias a los estudiantes de la Universidad Simón Bolívar.

En la investigadora surgió un interés por observar cómo los sujetos investigados formaban un esquema o perspectiva del problema de estudio a través de la interacción, por lo cual se optó también trabajar con grupos de enfoque.

Por su parte, Hernández (2010) considera que algunos autores ven los grupos de enfoque como una especie de entrevista grupal, las cuales consisten en reuniones de grupos pequeños o medianos (tres a diez personas), en las que los participantes conversan a profundidad en torno a uno o varios temas en un ambiente relajado e informal, bajo la conducción de un especialista en dinámicas grupales. El propósito con estos grupos fue observar la interacción entre ellos y cómo se construyeron grupalmente los significados; en este caso el proceso de socialización política al interior de la familia.

El paradigma asumido en esta investigación fue el histórico-hermenéutico, el cual permitió la comprensión e interpretación de los contextos y los textos desde las múltiples subjetividades, posibilitando una visión holística del fenómeno.

Para el desarrollo de la investigación se practicaron 25 entrevistas y se realizaron 3 grupos focales, los cuales contaron con 10 participantes cada uno.

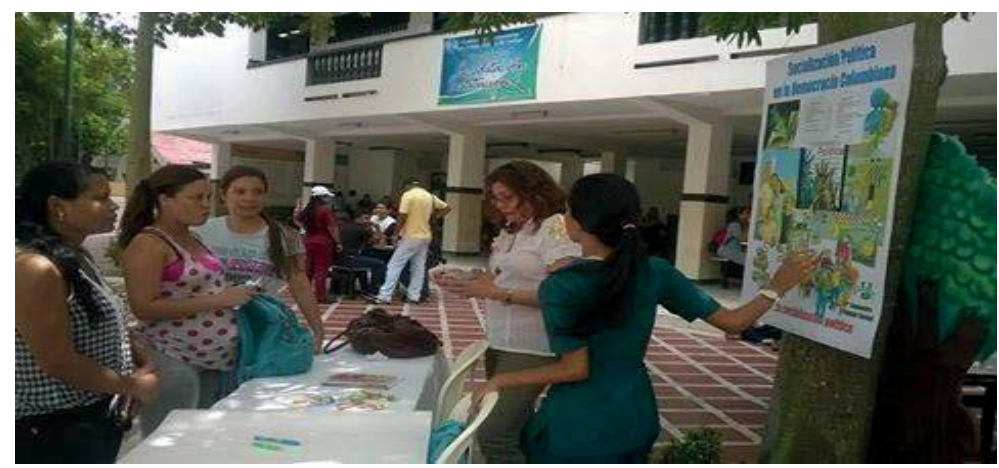

Registro fotográfico 1: Socialización del proyecto 


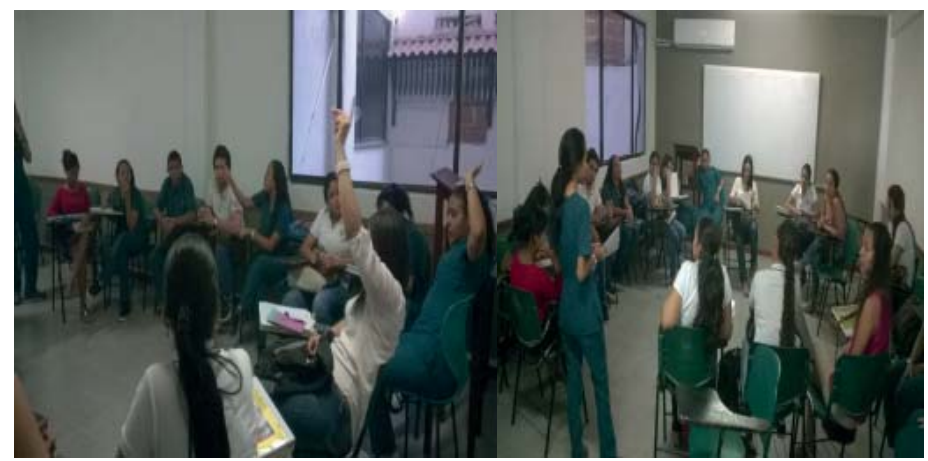

Registro Fotográfico 2: Participación en grupos focales.

\section{Validez y confiabilidad}

Son diferentes los aspectos a tener en cuenta en el proceso de validez y confiabilidad en la investigación cualitativa, pero para este estudio se tuvo en cuenta lo planteado por Burns, Schlozman y Verba (2001), que la credibilidad se logra mediante la corroboración estructural y la adecuación referencial.

La corroboración estructural es el proceso mediante el cual varias partes de los datos (categorías, por ejemplo) se soportan conceptualmente entre sí, e implica reunir los datos e información emergente para establecer conexiones o vínculos que eventualmente crean un todo, cuya justificación son las propias piezas de evidencia que lo conforman. Mientras que la adecuación referencial es la cercanía entre lo descrito y los hechos, acudir a varias fuentes de datos y registrar todas las dimensiones de los eventos y experiencias, es conveniente escuchar todas las voces; por ejemplo en las entrevistas estar pendiente de la comunicación verbal y no verbal.

Martínez (2006) hace su aporte significativo con relación a la confiabilidad y validez, asegurando que una investigación con buena confiabilidad es aquella que es estable, segura, congruente, igual a sí misma en diferentes tiempos y previsible para el futuro. Sobre el mismo tema el autor precisa que una investigación tiene un alto nivel de validez, si al observar una realidad, se aprecia esa realidad y no otra. Este hecho constituye la validez interna. Hay otro aspecto 
que es la validez externa, que consiste en averiguar hasta qué punto las conclusiones de un estudio son aplicables a grupos similares.

\section{Procedimiento para realizar la data}

Para el procesamiento de la información se trabajó con el software de análisis cualitativo ATLAS Ti versión 6.0, es un potente conjunto de herramientas para el análisis cualitativo de grandes cuerpos de datos textuales, gráficos y de video. La sofisticación de las herramientas ayudó a organizar, reagrupar y gestionar el material de manera creativa y, al mismo tiempo, sistemática. El ATLAS Ti permitió mantenerse centrado en el propio material de investigación, cualquiera que sea el campo de trabajo, y dio respuesta a las necesidades del análisis cualitativo.

\section{Resultados}

\begin{tabular}{|c|c|c|}
\hline \multicolumn{3}{|c|}{ Síntesis de los resultados } \\
\hline Observación & Entrevista & Grupo focal \\
\hline $\begin{array}{l}\text { Los estudiantes demostra- } \\
\text { ron poco conocimiento e } \\
\text { interés por los temas po- } \\
\text { líticos, ya que los asocian } \\
\text { con la corrupción y el } \\
\text { clientelismo. }\end{array}$ & $\begin{array}{l}\text { Con relación al tema de la } \\
\text { democracia manifestaron } \\
\text { que es el proceso o me- } \\
\text { canismo de participación } \\
\text { ciudadana en el cual las } \\
\text { personas ejercen sus de- } \\
\text { rechos de elegir y ser ele- } \\
\text { gidos. Para ellos la demo- } \\
\text { cracia está asociada con el } \\
\text { derecho a ejercer el voto. }\end{array}$ & $\begin{array}{l}\text { Prima la idea de que la } \\
\text { familia ha ejercido poco } \\
\text { liderazgo en el proceso de } \\
\text { socialización política, que } \\
\text { solamente se habla el tema } \\
\text { en épocas electorales. De } \\
\text { igual manera expresan } \\
\text { sentirse libres al momento } \\
\text { de tomar una decisión por } \\
\text { quién votar. }\end{array}$ \\
\hline $\begin{array}{l}\text { Sin embargo, en cuanto a } \\
\text { las preguntas relacionadas } \\
\text { con la democracia, la asu- } \\
\text { mieron con mayor enten- } \\
\text { dimiento. } \\
\text { Se observó poco conoci- } \\
\text { miento con el tema rela- } \\
\text { cionado con los valores } \\
\text { políticos. }\end{array}$ & & \\
\hline
\end{tabular}




\section{Conclusiones}

Muy a pesar de que la Constitución Política de Colombia reconoce la importancia de la familia y la democracia, el proceso de socialización política requiere replantearse por la importancia de los agentes socializadores, la cual es ampliamente reconocida.

En este sentido se sigue a Ácigas (2004), el cual expresa que la socialización política no se consume en la simple acumulación de conocimientos sin sentido u orden, ni en la repetición mecánica de conductas; por el contrario, requiere que el conocimiento transmitido y adquirido se estructure y organice para favorecer su internalización, el cual es el papel de los agentes socializadores, entre ellos la familia.

En Colombia hay muchas deficiencias en el conocimiento y promoción de la socialización política, específicamente en los agentes primarios (familia), y se requiere comprender la realidad actual. Dudley y Gitelson (2009) manifiestan que hay quienes sostienen la necesidad de avanzar en estudios que investiguen la relación de todos los agentes socializadores entre sí. Los resultados de la investigación muestran que, en su mayoría, los estudiantes universitarios desconocen a qué hace referencia el término socialización política y cuál es su connotación al interior de la familia.

Por otro lado los estudiantes relacionan el concepto de participación política directamente con el hecho de sufragar, además lo consideran como la forma en que participan en ella, desconociendo los otros valores de participación política.

(...) la participación política es asociada con una forma diferente de hacer política, la cual busca el mantenimiento de la comunidad a través de diversas actividades como el establecimiento de la comunicación pública para la solución de las disputas existentes y la cooperación entre los miembros individuales y grupales pertenecientes a la comunidad en cuestión. (Franco y Flores, 2009, p.82) 
En la actualidad, especialmente en los países latinoamericanos, la democracia vive una transición en el ser y el deber ser, lo cual quiere decir que los principios que rigen la democracia no se hacen visibles.

Araújo (2007) expresa que "La democracia no solo es un régimen político. También es un conjunto de procedimientos de decisión que requieren instituciones concretas concebidas para generar acuerdos" (p.83). Además agrega que la vigencia de la democracia supone la defensa del pluralismo y de la participación.

Se puede colegir que en esencia, la democracia trasciende de un régimen político a uno ético-político, el cual brinda la garantía de participación igualitaria de los ciudadanos a través de los diversos mecanismos de participación política.

La familia contemporánea desarrolla el proceso de socialización sin imposición, pero a su vez puede estar influenciada por los factores ambientales, los cuales son determinantes en el proceso de socialización política; sin embargo, los jóvenes manifestaron que toman sus propias decisiones y que también reciben influencias de otros agentes de socialización, lo cual hace que no estén apegados a las ideas políticas de sus padres, ya que la socialización política no es dada por la familia permanentemente sino en época pre-electoral; de ahí su asociación con el voto.

Lo anterior permite concluir que la familia como agente de socialización política en la democracia colombiana, aún conserva su rol, pero requiere de mayor compromiso en su función socializadora y en la interiorización de los valores políticos en cada uno de sus miembros.

\section{Referencias Bibliográficas}

Asamblea Nacional Constituyente de Colombia. “Constitución Política de Colombia” (1991). Bogotá D.C., Colombia, editorial Unión Ltda. 2012. 
Anduiza, E. y Bosch, A. (2004). Comportamiento Político y Electoral. Primera Edición. Barcelona, España.

Araújo (2007). Balance del Desarrollo Electoral Democrático. Primera edición. Editorial. Universidad del Rosario P. Bogotá, Colombia.

Arciga, S. (2004). Del Pensamiento Social a la Participación: Estudios de Psicología Social. Primera edición. México: Editorial Sociedad Mexicana de Psicología Social AC.

Barreda, M. (2006). Las bases subjetivas de la política. En: La Democracia Española: Realidades y Desafíos. Análisis del Sistema Político Español. Primera edición. Compilado por Barreda, Mikel y Borge, Rosa. Barcelona, España: Editorial UOC. Burns, Nancy y Grove, Susan K. Investigación en enfermería. 3 ed. Saunders Company.

Benedicto, J. (2005). La Construcción de los Universos Políticos de los Ciudadanos. En: Moran, Maria Luz. (EDS) Temas de sociedad política. Madrid, España: Editorial Alianza.

Burns, N; Schlozman, K; Verba, S. (2001). The Private Roots of Public Action. Gender, Equality, and Political Participation. Cambridge: Harvard University Press.

Campbell, A; Converse, P; Miller, W \& Stokes, D. (1960). The American Voter. New York, USA: University of Michigan.

Cardús, S. (2003). La Mirada del sociólogo: qué es, qué hace, qué dice la Sociología. Primera edición. Barcelona, España: Editorial UOC.

Conway, M. (1986). La participación política en los Estados Unidos, México D. F: Ediciones Gernika.

Downs, A. (1957). An Economic Theory of Democracy. New York, Haper Collins: en Español: Teoría económica de la democracia. Madrid, España: Ed. Aguilar.

Franco, B. y Flórez, J. (2009). Aproximación teórico-Conceptual de la participación electoral, una discusión aún abierta. Revista Desafíos, 21, 259275.

García, Y. (2008). Familias en Colombia Transiciones hacia el Siglo XXI. Barranquilla-Colombia: Editorial Corporación Educativa Mayor del Desarrollo Simón Bolívar. 
Greenstein, F. (1965). Children and Politics. USA. Yale University Press. Hyman, H. (1959). Political Socialization. Glencoe: Free Press.

Hernández, R., Fernández, C., Baptista, M. (2014). Metodología de la investigación. Sexta edición. México. McGraw-Hill Education, p.600.

Jaime, C. (2000). Familia y socialización política. La transmisión de orientaciones ideológicas en el seno de la familia española. Revista Española de investigaciones sociológicas, 92. Madrid, España: Centro de Investigaciones sociológicas.

Martínez, M. (2006). Ciencia y Arte en la Metodología Cualitativa. 2ed. México, México: Trillas. p.198.

Milbrath, L. \& Goel, M. (1977). Political participation. Chicago: Rand McNally. Molina, J. (2000). Comportamiento Electoral en Venezuela 1998-2000: cambio y Continuidad. Cuestiones políticas 25.

Pasquino, G. (1988). Naturaleza y evolución de la disciplna. En Manual de Ciencia Política. Madrid: Alianza.

Pérez, C. (2006). Enfoques Teórico-Metodológicos en el Estudio de la Participación Electoral. Cuestiones Políticas V. Maracaibo, Venezuela. Universidad del Zulia, Facultad de Ciencia Política, 22(37) 11-141.

Pereira, V. (2001). El partidismo en la familia venezolana: de viejas pasiones a nuevas atracciones. Año 5, No. 9, Enero-Junio, 2001. Universidad del Zulia, Instituto de Estudios Políticos y Derecho Público, Maracaibo, Zulia. Venezuela. 12(2) 176-202.

Percheron, A. (1990). Production et transmission des valeursausein de la famille, en VV. AA., Du politique et du social dansl'avenir de la famille, La Documentation Française, París, pp.131-139.

Rincón, M. (2012). La Familia como Escenario de Socialización para la Convivencia Ciudadana. Universidad del Valle. Revista Eleuthera, 7, 16-132.

Sandoval, J. y Díaz, F. (2010). Socialización política y juventud: el caso de las trayectorias ciudadanas de los estudiantes universitarios de la región de Valparaíso. Ultima decad. [Online], 18(32), 11-36.

Sartori, G. (1988). Teoría de la Democracia. El debate contemporáneo. Madrid, España: Alianza Editorial, S. A.

Tonon, G. (2009). Comunidad, Participación y Socialización Política. Primera 
Edición. Buenos Aires, Argentina: Editorial Espacio.

Vásquez, R. (2010). Compromiso cívico y democracia. Sevilla: Fundación pública Andaluces Centro de Estudio Andaluces.

\section{Hemerográficas}

Arnoletto, E. (2007). Curso de Teoría Política. Capítulo 6. Los Modelos de Integración y Orden. Recuperado de: http://www.eumed.net/libros- gratis/2007b/300/indice.htm.

Dudley, R. Gitelson, A. (2009). Political lteracy, Civic Education and Civic Engagement: A Return to Political Socialization. APP died De velopmental science, 4, 171-182. Recuperado de http://www.tandfonline.com/doi/ abs/10.1207/S1532480XADS0604_3\#.U8rs9uN5PSk.

Montero, J., Torcal, M. y Font, J. (2006). Ciudadanos, Asociaciones y Participación en España. pp.167-169. Recuperado de https://books.google.com. co/books?id=bgJ3QPqRMTcC\&redir_esc $=y$

Puga, M., Perchard, J., Castro, T. (2007). Hacia la sociología. Cuarta edición. México, México. Pearson pp.215-216. Disponible en línea en: http:// es.slideshare.net/nipi1612/hacialasociologia4edpuga

Villaroel, G. (2001). Las Representaciones Políticas del venezolano: Un Estudio Sobre Cultura Política. SE. Caracas, Venezuela. Universidad Central de Venezuela. p.61. Recuperado de https://books.google.com.co/ books?id=H8pK4ViakZEC\&pg=PA20\&lpg=PA20\&dq=Las+Representaciones+Pol\%C3\%ADticas+del+Venezolano:+Un+Estudio+Sobre+Cultura + Pol\%C3\%ADtica\&source $=$ bl\&ots $=$ k9QY3m0Oze\&sig $=$ glASEvgLodQ5aL1hIQeA3QQEbWY\&hl=es\&sa=X\&ved=0ahUKEwi0htPrnaPMAhUF5SYKHQvfBmAQ6AEIGjAA\#v=onepage\&q=Las\%20 Representaciones\%20Pol\%C3\%ADticas\%20del\%20Venezolano\%3A\%20Un\%20Estudio\%20Sobre\%20Cultura\%20Pol\%C3\%ADti$\mathrm{ca} \& \mathrm{f}=$ false . 